\title{
ESTÁGIO DE DESENVOLVIMENTO DO ARRANJO PRODUTIVO LOCAL DE CONFECÇÕES DO MUNICÍPIO TORITAMA (PE)
}

\author{
Dandra Maria Araújo de Souza ${ }^{1}$ (D) Paloma Rayanne Silva Bezerra $^{2}$ (D) Gêuda Anazile da Costa Gonçalves ${ }^{3}$ \\ ${ }^{1}$ Doutora, Universidade Federal de Campina Grande-UFCG. Campina Grande, Paraíba - Brasil. sandra.adm@hotmail.com \\ ${ }^{2}$ Bacharela, Universidade Estadual da Paraíba - UEPB. Campina Grande, Paraíba-Brasil.adm.pbezerra@ gmail.com \\ ${ }^{3}$ Doutora, Universidade Federal de Campina Grande - UFCG. Campina Grande, Paraíba - Brasil. geuda_@hotmail.com
}

\section{Resumo}

Objetivo do Trabalho: Classificar o estágio de desenvolvimento do Arranjo Produtivo Local de confecções do município de Toritama - PE.

Metodologia: A pesquisa é exploratória e descritiva, com abordagem qualitativa conduzida sob a forma de estudo de caso. Os dados primários foram levantados por meio de entrevista semiestruturada e de observação não participante, complementadas com o auxílio do diário de campo. As demais informações foram obtidas por meio de fontes secundárias, em especial, de pesquisas de campo realizadas anteriormente no setor de confecções. O instrumento de coleta de dado foi elaborado a partir do modelo proposto pelo Sebrae (2014), que classifica os Arranjos em: Incipientes, em Desenvolvimento e Desenvolvidos. Quanto à análise dos dados, utilizou-se da técnica de análise de conteúdo (Bardin, 2016).

Originalidade: $\mathrm{O}$ estudo constata limitações e oportunidades que podem auxiliar no estabelecimento de estratégias de apoio ao APL confeccionista de Toritama (PE) em relação ao ciclo de vida, por meio de entrevista semiestruturada e de observação não participante, complementadas com o auxílio do diário de campo de um modelo desenvolvido especificamente para a realidade brasileira.

Principais Resultados: Os resultados demonstraram que o APL está no estágio incipiente, dado que o setor possui um ambiente propício às relações de cooperação. Entretanto, as empresas atuam com foco individual, e as lideranças locais não se envolvem de forma proativa no progresso das organizações.

Contribuições Teóricas: Este trabalho contribuiu com a ampliação dos debates sobre o ciclo de vida de APLs, bem como consolidou informações sobre um dos APLs de confecções mais relevantes para a economia do Estado de Pernambuco, possibilitando identificar os aspectos passíveis de melhorias e a redefinição de políticas de apoio à evolução do setor.

Palavras-chave: Arranjo produtivo local. Estágio de desenvolvimento. Setor de confecções.

\section{DEVELOPMENT STAGE OF THE LOCAL PRODUCTION ARRANGEMENT OF CONFECTIONS OF THE MUNICIPALITY TORITAMA (PE)}

\section{Abstract}

Objective: Classify the development stage of the Local Productive Arrangement of clothing in the municipality of Toritama - PE.

Methodology: The research is exploratory and descriptive, with a qualitative approach conducted in the form of a case study. The primary data were collected through semi-structured interview and non-participating observation, complemented with the help of the field diary. The other information was obtained through secondary sources, especially field surveys previously conducted in the clothing industry. The data collection instrument was based on the model proposed by Sebrae (2014), which classifies the Arrangements into Incipient, under Development and Developed. As for data analysis, the content analysis technique was used.

Originality: The study finds limitations and opportunities that may help in establishing support strategies for APL confectionery in Toritama - PE in relation to the life cycle, through a model developed specifically for the Brazilian reality.
Main results: The results showed that APL is in its early stages, given that the sector has an environment conducive to cooperative relationships, however, companies act with individual focus, and local leaders are not proactively involved in the progress of organizations.

Theoretical Contributions: This work has contributed to expanding the debates on the life cycle of APLs, as well as consolidating information on one of the most relevant clothing APLs for the economy of the State of Pernambuco, making it possible to identify aspects that could be improved and to redefine policies to support the evolution of the sector.

Keywords: Local productive arrangement. Development stage. Clothing sector.

\section{FASE DE DESARROLLO DE LA PRODUCCIÓN LOCAL DE CONFECCIONES DEL MUNICIPIO DE TORITAMA (PE)}

\section{Resumen}

Objetivo del trabajo: Clasificar la etapa de desarrollo del Arreglo Productivo Local de ropa en el municipio de Toritama - PE.

Metodología: La investigación es exploratoria y descriptiva, con un enfoque cualitativo realizado en forma de estudio de caso. Los datos primarios se reunieron mediante entrevistas semiestructuradas y observación no participante, complementadas con la ayuda del diario de campo. El resto de la información se obtuvo a través de fuentes secundarias, especialmente de estudios de campo realizados anteriormente en la industria del vestido. El instrumento de recopilación de datos se basó en el modelo propuesto por el Sebrae (2014), que clasifica los Arreglos en Incipiente, en desarrollo y desarrollada. En cuanto al análisis de los datos, se utilizó la técnica de análisis de contenido.

Originalidad: El estudio encuentra limitaciones y oportunidades que pueden ayudar en el establecimiento de estrategias de apoyo para los confiteros de APL en Toritama - PE en relación con el ciclo de vida, a través de un modelo desarrollado específicamente para la realidad brasileña.

Principales resultados: Los resultados han demostrado que la LPA está en sus inicios, dado que el sector cuenta con un entorno propicio para las relaciones de cooperación, sin embargo, las empresas actúan con un enfoque individual y los dirigentes locales no participan activamente en el progreso de las organizaciones.

Contribuciones teóricas: Esta labor ha contribuido a ampliar los debates sobre el ciclo de vida de las MAP, así como a consolidar la información sobre una de las MAP de prendas de vestir más relevantes para la economía del Estado de Pernambuco, lo que ha permitido identificar los aspectos que podrían mejorarse y redefinir las políticas de apoyo a la evolución del sector.

Palabras-claves: Arreglo productivo local. Pasantía de desarrollo. Sector del vestido.

\section{Cite as / Como citar}

American Psychological Association (APA)

SOUZA, S. M. A., BEZERRA, P. R. S., \& GONÇALVES, G. A. da C. (2020, Oct./Dec.). Estágio de desenvolvimento do arranjo produtivo local de confecções do município Toritama (PE). Iberoamerican Journal of Strategic Management (IJSM), 19(4), 100-118. https://doi.org/10.5585/riae.v19i4.17368.

Toritama (PE). Iberoamerican Journal of Strategic Management (IJSM),v. 19, n. 4, p. 100-118, Oct./Dec. 2020. https://doi.org/10.5585/riae.v19i4.16310. 


\section{Introdução}

Os Arranjos Produtivos Locais (APLs) podem ser definidos como aglomerados de empresas em volta de uma atividade comum, que contam com a presença de organizações relacionadas e de instituições de apoio. Esse conceito foi criado tendo como exemplo as experiências de aglomerados econômicos iniciados nas décadas de 1960 e 1970 na Alemanha e na Itália. Sua formação é, geralmente, vinculada a trajetórias históricas de construção de identidades e de formação de vínculos territoriais, a partir de bases social, cultural, política e econômica comum. Pressupõem-se, nos APLs, ambientes favoráveis à interação, à cooperação e à confiança entre os atores, além de potencial para desenvolvimento (Sebrae, 2014).

Apesar das possibilidades de ganhos proporcionadas por esses Arranjos, nem todos se configuram como casos de sucessos, devido às dificuldades encontradas no sentido da promoção efetiva do estabelecimento de redes e da cooperação baseadas na confiança e na minimização das desigualdades entre os atores sociais (Souza, Bezerra, Rocha, \& Gonçalves, 2020). Assim, os APLs estão continuamente sujeitos a contingências oriundas de eventos inesperados e de tomada de decisões sob um conjunto de restrições, bem como às características das organizações, da dinâmica estrutural e da governança. Esses aspectos tendem a criar regularidades no ciclo de vida dos APLs (Martin \& Sunley, 2011). Além disso, ao projetar programas e políticas, os formuladores geralmente não fazem diferenciação entre as fases do ciclo de vida dos APLs. Portanto, as mesmas medidas são aplicadas a todos os APLs suportados em um programa ou política (Brenner \& Schlump, 2011).

Nesse sentido, averiguar o estágio de desenvolvimento dos APLs é necessário para que seja possível identificar limitações e oportunidades para traçar políticas de apoio adequadas a contextos espaciais específicos. As políticas que visam a promoção de APLs, para serem efetivas, devem considerar as especificidades de cada APL, o fortalecimento e a ampliação dos instrumentos de comunicação e de controle social, buscando alinhar ações do poder público e interesses da sociedade (Tizziotti, Truzzi, \& Barbosa, 2019).

Estudos que contribuíram para a ampliação deste campo temático evidenciaram que a abordagem do ciclo de vida de APLs vem sendo aplicada em vários contextos, bem como o desenvolvimento dessas estruturas organizacionais pode estar associado a diferentes fatores (políticos, tecnológicos, aprendizagem, etc.). Esses aspectos podem ser consultados, por exemplo, nos seguintes estudos: Elola, Valdaliso, Franco e López (2017) analisaram a relevância dos diferentes tipos de políticas para o surgimento e para a evolução de APLs fixados no País Basco, atuantes nas indústrias de papel, de máquinas, etc. Ostergaard e Park (2015) estudaram o processo de declínio do APL de comunicação sem fio na Dinamarca, destacando os principais fatores que conduziram o Arranjo para esta fase, a exemplo do aprisionamento tecnológico e da saída de empresas-chave do setor. Dyba, Stryjakiewicz e De Marchi (2019) investigaram APLs do setor mobiliário, situados em diferentes estágios de seu ciclo de vida, destacando as fontes de conhecimentos utilizadas por esses aglomerados, como cooperação com universidades, treinamentos, etc. 
Este estudo objetiva classificar o estágio de desenvolvimento do Arranjo Produtivo Local de confecções no município de Toritama (PE), a partir da classificação de Arranjos Produtivos Locais proposta pelo Sebrae (2014), que divide os APLs em: Incipientes, em Desenvolvimento e Desenvolvidos. Esse modelo foi selecionado em razão da possibilidade de enfoque analítico-sistêmico das dinâmicas de APLs, bem como pelo fato de ser direcionado à realidade brasileira.

Desse modo, a pesquisa pauta-se na seguinte indagação: Qual o estágio de desenvolvimento do Arranjo Produtivo Local de confecções situado no município de Toritama (PE)? O setor foi selecionado em razão de sua importância para o desenvolvimento econômico do referido município e do Estado de Pernambuco, bem como pela necessidade da criação e da aplicação de estratégias que favoreçam a ascensão das vantagens competitivas.

A importância deste estudo é refletida na ampliação dos debates atuais sobre o ciclo de vida desses Arranjos, bem como na possibilidade que o mesmo tem de apontar adequações necessárias à evolução do APL estudado, a partir de abordagens e de metodologias consolidadas que tratam sobre o desenvolvimento desse de APLs. Assim, o estudo poderá contribuir para a compreensão dos aspectos que possibilitam o incremento de vantagens competitivas e a evolução destes formatos organizacionais, bem como para que as lideranças locais melhorem suas formas de atuação quanto às ações direcionadas ao APL.

O escrito está organizado do seguinte modo: além da presente introdução, a segunda seção trata sobre os Arranjos Produtivos Locais, o Ciclo de vida de APLs e a metodologia utilizada para a classificação destes proposta pelo Sebrae (2014). A terceira seção apresenta os procedimentos metodológicos utilizados para a realização desta pesquisa. Em seguida, é apresentada a análise dos resultados e, por fim, a quinta seção trata das considerações finais.

\section{Fundamentação teórica}

\subsection{Arranjos produtivos locais}

A atenção antes voltada para como as tecnologias, as demandas, as finanças e as políticas setoriais exerciam atuação sobre a competitividade das empresas, está se voltando agora para os aglomerados setoriais, que por meio de cooperação criam diferenciais competitivos consideráveis para as organizações ali concentradas (Silva, Araújo, Souza, \& Gonçalves, 2015).

As aglomerações de empresas que atuam no mesmo setor de atividade econômica fornecem uma dinâmica de desenvolvimento econômico vantajosa, tais como: mão de obra especializada, proximidade física de fornecedores, produção de conhecimento e de tecnologia, etc (Tizziotti et al., 2019). Os aglomerados econômicos são caracterizados a partir de distintos critérios, a saber: quantidade de pequenas e médias empresas concentradas, índices de especialização da produção de determinados bens, existência de relacionamentos formais e informais, dentre outros (Araújo, Silva, Souza, Lacerda, \& Gonçalves, 2016). 
A ênfase direcionada para esta nova estrutura organizacional favoreceu o surgimento de termos diferenciados, como: Clusters, Distritos Industriais, Arranjos Produtivos Locais - APLs, etc. Esses conceitos são todos relacionados com a aglomeração de empresas. No entanto, existem algumas diferenças, a saber: o cluster está relacionado a uma concentração setorial de indústrias conectadas, o distrito industrial implica em uma concentração geográfica de empresas e instituições locais. Já o APL pode ser concebido como uma instância superior, pois é uma aglomeração de empresas com atores econômicos, políticos e sociais que podem promover produção e inovação por meio da cooperação e da aprendizagem (Alderete \& Bacic, 2018).

Este estudo foca sua análise nos Arranjos Produtivos Locais (APLs), devido à atenção que vêm recebendo de órgãos públicos e de instituições privadas como alternativa para o desenvolvimento local. APLs são aglomerações de empresas e empreendimentos, fixados em um mesmo território, que apresentam especialização produtiva, algum tipo de governança e mantêm vínculos de articulação, de interação, de cooperação e de aprendizagem entre distintos atores locais, tais como: governo, associações empresariais, instituições de crédito, de ensino e de pesquisa, entre outros (Brasil, 2018).

Nas últimas décadas, os APLs têm requerido grande relevância nos estudos organizacionais por apresentarem uma proposta de resposta aos novos desafios de competitividade presentes em mercados de constantes inovações e transformações tecnológicas. Sua relevância é reconhecida não somente no que diz respeito ao engrandecimento de competitividade das empresas, mas também em relação à formação de empregos e de renda, o que resulta em desenvolvimento socioeconômico (Iacono \& Nagano, 2009).

Os APLs permitem sistematizar e coordenar as relações entre os atores sociais visando a geração de desenvolvimento e o alcance de objetivos e de metas locais e regionais. Neste processo, a cooperação e a confiança são características pré-existentes facilitadoras da criação e da manutenção desses relacionamentos (Lübeck, Wittmann, \& Silva, 2019). Altos níveis de articulação podem beneficiar todos os membros de um APL, otimizando os processos de produção e o desenvolvimento de produtos, melhorando a capacidade de atender às demandas de mercado. Entretanto, promover essa integração entre múltiplos atores é uma tarefa difícil, pois exige gestão, mudança de valores, visão estratégica e sistêmica (Oprime, Tristão, \& Pimenta, 2011).

Observa-se que o desenvolvimento de APLs é moldado por uma multiplicidade de fatores em diferentes escalas espaciais e suas interações. No entanto, é adequado argumentar que esses aspectos vinculados à evolução de APLs ainda são mal compreendidos, pois a literatura tem dedicado relativamente pouca atenção ao ciclo de vida de APLs (Trippl, Grillitsch, Isaksen, \& Sinozic, 2015).

Deste modo, embora a existência dessas estruturas organizacionais não seja um fato recente, os APLs ganharam muita atenção nos últimos anos (Prado, Moreno Ferragi, Gama Boaventura, \& Telles, 2013). Existem várias teorias e conceitos a respeito do surgimento e do desenvolvimento desses aglomerados econômicos, mas a abordagem do ciclo de vida de APLs ainda é embrionária (Brenner \& Schlump, 2011). Pouco se sabe sobre como os APLs evoluem ao longo do tempo e por que alguns declinam. 
Esse assunto é de grande interesse para os formuladores de políticas, pois o declínio provocará impactos adversos nas economias regionais (Martin \& Sunley, 2011). A próxima seção traz aspectos básicos para a compreensão desse campo da literatura especializada que aborda a evolução de APLs.

\subsection{Ciclo de vida de arranjos produtivos locais}

A abordagem do ciclo de vida de APLs pode contribuir para além das perspectivas dominantes na literatura especializada sobre aglomerados econômicos, ampliando a compreensão dos fatores que podem desencadear o desenvolvimento de APLs (Trippl et al., 2015). A maioria das pesquisas sobre o tema está concentrada no estudo de vantagens competitivas. Nesse sentido, o desenvolvimento de estudos sobre a dinâmica de aglomerados produtivos representa uma questão importante para acadêmicos e para formuladores de políticas, em especial, quanto ao planejamento adaptativo e proativo do desenvolvimento regional (Gancarczyk \& Bohatkiewicz, 2018).

Os APLs estão constantemente expostos às influências externas resultantes de transformações do mercado. Assim, a capacidade de um arranjo se adaptar às mudanças é determinante para o seu desenvolvimento (Ostergaard \& Park, 2015). Segundo Martin e Sunley (2011) existem interações entre aglomerados produtivos e seus ambientes, bem como diferentes trajetórias de desenvolvimento. Para os autores, a evolução de um APL engloba quatro fases, a saber: exploração, reorganização, conservação e liberação. Entre as trajetórias, o declínio será resultado de uma rigidez interna, indicando uma capacidade adaptativa insuficiente, essa capacidade é considerada um dos atributos importantes de um aglomerado que muda ao longo das fases do ciclo adaptativo.

De acordo com Menzel e Fornahl (2011), o ciclo de vida de APLs abrange as seguintes etapas: emergência, crescimento, sustentação e declínio. Ademais, os autores defendem que a diversidade e a heterogeneidade do conhecimento fornecem a base para o progresso desses agrupamentos. Isto é, o desenvolvimento de um potencial APL pode ser interrompido em qualquer estágio do ciclo de vida quando sua heterogeneidade não pode ser sustentada.

Para Brenner \& Schlump (2011), embora exista um quarto estágio (declínio), várias abordagens sobre o ciclo de vida de aglomerados locais parecem concordar com a existência de três estágios: estágio inicial, estágio de expansão, e estágio maduro. Os autores defendem que o estágio maduro e a fase de declínio às vezes não são distinguidos, pois a principal diferença entre ambos é que no estágio de declínio a produção é reduzida fortemente, a situação do mercado se torna difícil. Portanto, o APL é forçado a declinar ou a se transformar considerando novas possibilidades de atuação.

Por sua vez, o Serviço Brasileiro de Apoio às Micro e Pequenas Empresas - Sebrae (2014) destaca que cada APL apresenta suas próprias características em relação às origens, ao cenário econômico, ao ambiente sociocultural e ao grau de complexidade da cadeia produtiva. Assim, quanto ao desenvolvimento, os APLs apresentam variações e podem ser classificados em três estágios: incipiente, em desenvolvimento e desenvolvidos. 
Em resumo, a abordagem do ciclo de vida de APLs precisa ser reconhecida por inserir uma perspectiva dinâmica à literatura especializada, pois se concentra em vários aspectos que impulsionam a evolução dos APLs, tais como: a evolução de indústrias, o avanço de tecnologias, a heterogeneidade das capacidades da organização, os processos de aprendizagem, entre outros (Trippl et al., 2015).

O modelo do Sebrae (2014) concebe APLs como aglomerações de empresas do mesmo setor ou correlatas em um mesmo espaço geográfico, com a presença de atores econômicos, políticos e sociais, e que possuem vínculos e interdependência, num ambiente de especialização produtiva, ou seja, são sistemas dinâmicos cuja interdependência, articulação e vínculos entre diferentes atores determinam a sua competitividade e a sua evolução.

A partir da definição teórica de APLs e da capacidade do enfoque analítico das dinâmicas desses aglomerados produtivos, manifesta-se como oportuno a aplicação do modelo proposto pelo Sebrae (2014). Outra justificativa para a seleção do referido modelo, diz respeito ao fato de que o mesmo foi desenvolvido especificamente para a realidade brasileira. Assim, a próxima seção consiste na apresentação das características do modelo utilizado como suporte científico para classificar o estágio de desenvolvimento do APL estudado.

\subsection{Classificação de arranjos produtivos locais - modelo proposto pelo Sebrae (2014)}

Os Arranjos Produtivos Locais (APLs) podem ser classificados da seguinte forma: i) Incipiente, são APLs caracterizados pela ausência de integração entre as empresas, o poder público e os atores sociais institucionais; ii) em desenvolvimento, os APLs são considerados significantes para o desenvolvimento local, existe a preocupação com os diversos elos da cadeia produtiva, as lideranças são mais capacitadas e existe uma incipiente interação entre os atores sociais e; iii) desenvolvidos, são APLs onde a articulação entre os atores viabiliza a inovação de produtos e os ganhos de experiência e de conhecimento, os atores sociais exercem forte impacto sobre a região onde estão inseridos a partir de objetivos e de estratégias comuns (Sebrae, 2014).

O Quadro 1 apresenta as categorias e seus respectivos estágios de desenvolvimento, bem como os critérios analisados nesta pesquisa. 
Quadro 1 - Classificação de Arranjos Produtivos Locais Categorias e estágios de desenvolvimento Liderança

I: As lideranças locais não são conhecidas, priorizam o desenvolvimento de suas empresas, e não do setor.

ED: As lideranças estão mais conhecidas e qualificadas, privilegiam o trabalho setorial. São efetuadas iniciativas coletivas de compra, venda e acesso a instrumentos produtivos de tecnologia avançada.

D: As lideranças atuam em entidades de classe, conselhos municipais e regionais em prol do arranjo, há regras formais de concordância entre os líderes.

\section{Atores e Cooperação}

I: Não há unidades de classe ou são timidamente desenvolvidas. A associação e o consenso entre as lideranças locais são escassos.

ED: Unidades de classe auxiliam nas decisões políticas que influem no desenvolvimento. Determina-se uma cooperação intersetorial das empresas com seus fornecedores e suas organizações.

D: As empresas estão estruturadas em entidades desenvolvidas, operam nos níveis regionais, estaduais e nacional.

Critérios do estudo

Associação com outros atores; Ações para a disseminação de informações; Tipos de informações trocadas entre os agentes; Exigência de reciprocidade das lideranças locais; Iniciativas apontadas para a compra e venda de mercadorias.

\section{Recursos Financeiros}

I: As instituições financeiras não se envolvem de maneira proativa no desenvolvimento das organizações empresariais.

ED: As empresas dispõem capitais particulares para garantir aplicações relevantes.

D: As empresas, mais bem organizadas, aplicam mais no

Iniciativas de cooperação entre as organizações; Critérios para a escolha dos parceiros; Mecanismos utilizados para disseminar informações; Punições em casos de deserção; Integração do poder público com o empresariado. desenvolvimento do arranjo, com fundos particulares e de terceiros.

\section{Gestão do Processo de Desenvolvimento}

I: Ausência de um programa com iniciativas integradas orientadas para o desenvolvimento.

ED: Inicia-se um elo entre as empresas e o poder público, especialmente na gestão de questões associadas ao desenvolvimento econômico.

D: Há um programa extenso estabelecido pelos parceiros governamentais e empresariais, abrangendo uma distribuição de tarefas para cada um dos atores incluídos.

\section{Inovação e Tecnologia}

I: Não há núcleos de profissionalização ou de pesquisa, para facilitar a criação de novos processos produtivos, ademais os empresários participam casualmente em feiras do setor.

ED: As empresas utilizam núcleos de educação profissional e de melhoramento técnico, possuem disposição em investir em novas tecnologias e novos produtos, estão regularmente em feiras do setor.

D: Há núcleos de pesquisa e instituições de ensino superior com programas específicos para o APL, e centros de educação profissional.

Linhas de crédito voltadas para o setor; Origem do capital de giro na ausência de linhas de crédito; Investimentos no desenvolvimento dos arranjos por parte de empresas.

A região torna-se exemplo para temas de inovação tecnológica referentes ao arranjo.

\section{Mercado e Competitividade}

I: O produto não possui forte identidade local, o mercado regional é conhecido e moderadamente atendido pelo arranjo. Os demais mercados são pouco acessíveis ou inacessíveis.

ED: O produto começa a ser identificado com propriedade sociocultural da região. Há pesquisas mercadológicas e referentes a inovações técnicas de modo frequente.

D: Empresas mais competitivas e atuam em diferentes esferas de mercado, tais como: o âmbito regional, o nacional e o internacional.

Ações por parte do governo voltadas para o setor; Gestão do Processo de Desenvolvimento; Políticas de desenvolvimento do APL por parte das organizações.

Atuação de centros de pesquisas para inovações e tecnologia das confecções e dos núcleos profissionalizantes; Investimentos na geração de inovação e tecnologia; Presença das empresas em eventos e feiras do setor.

Competitividade entre os estandes da feira; Contribuições que as parcerias proporcionam para a melhoria na competitividade das empresas e para o desenvolvimento local; Existência de pesquisas para identificar novos mercados e novos clientes; Identidade dos produtos; Nível de atuação no mercado.

Estágios de desenvolvimento de APLs: Incipiente (I), Em desenvolvimento (ED) e Desenvolvido (D).

Fonte: Sebrae (2014). 
Como pôde ser observado, o modelo elaborado pelo Sebrae (2014) permite identificar os pontos que interferem no desenvolvimento dos Arranjos Produtivos Locais, sendo possível visualizar o desempenho geral e de forma segmentada, o que pode ser utilizado como subsídio às lideranças locais no estabelecimento de estratégias e de políticas orientadas para o desenvolvimento local considerando as especificidades de cada recorte geográfico estudado.

\section{Procedimentos metodológicos}

O estudo tem como objetivo classificar o estágio de desenvolvimento do Arranjo Produtivo Local de confecções no município de Toritama (PE). A pesquisa é descritiva de caráter exploratório com abordagem qualitativa conduzida sob a forma de estudo de caso.

A pesquisa é caracterizada como exploratória por buscar compreender o problema enfrentado pelo pesquisador, bem como levantar ideias e informações. É o tipo de pesquisa utilizada para definir o problema com mais precisão, a partir da identificação dos cursos relevantes de ação ou da obtenção de dados essenciais para o desenvolvimento de determinado estudo (Malhotra, 2012).

O estudo de caso é utilizado em muitas situações para contribuir ao nosso conhecimento de fenômenos individuais, grupais, organizacionais, sociais, políticos e relacionados. Ele consiste em uma investigação empírica que estuda um fenômeno (caso) contemporâneo em profundidade e em seu contexto de mundo real, sobretudo, quando os limites entre o fenômeno e o contexto não puderem ser explicitamente evidentes (Yin, 2015).

O estudo foi realizado em um dos principais APLs do setor de confecções do agreste de Pernambuco. O APL confeccionista do Agreste pernambucano concentra sua atividade em dez municípios. Entretanto, três em especial sobressaem-se e normalmente são mencionados como os principais municípios do APL, são elas: Toritama, Caruaru e Santa Cruz do Capibaribe. Essas cidades estão em evidência por apresentarem um desempenho bem-sucedido em decorrência da produção e da venda de produtos de vestuário e por participarem de modo efetivo na formação do PIB estadual (Sebrae, 2012). Esses três municípios apresentaram para o ano de 2015 um elevado PIB, conforme pode ser constatado na Tabela 1.

Tabela 1 - Indicadores demográficos e econômicos 2015-2017

\begin{tabular}{|c|l|l|l|}
\hline $\begin{array}{c}\text { Indicadores Demográficos e } \\
\text { Econômicos }\end{array}$ & \multicolumn{1}{|c|}{ Toritama } & Caruaru & \multicolumn{1}{|c|}{$\begin{array}{c}\text { Santa Cruz } \\
\text { do Capibaribe }\end{array}$} \\
\hline PIB 2015 (em mil reais) & $571.086,81$ & $6.118 .029,84$ & $1.246 .844,77$ \\
\hline PIB per capita 2015 (em reais) & $13.557,60$ & $17.626,74$ & $12.286,00$ \\
\hline $\begin{array}{c}\text { Área territorial 2016 (km }{ }^{2} \text { ) } \\
\text { Contagem da população 2017 } \\
\text { (habitantes) }\end{array}$ & 25,704 & 920,61 & 335,309 \\
\hline $\begin{array}{c}\text { Densidade Demográfica 2017 } \\
\text { (hab./km) }\end{array}$ & 44.189 & 356.128 & 105.761 \\
\hline
\end{tabular}

Fonte: IBGE (2018a, 2018b, 2018c). 
Apesar de os três municípios apresentarem destaque para a economia, este estudo foca sua análise na cidade de Toritama, referência nacional na produção do jeans. Este APL é reconhecido pela relevância para o desenvolvimento econômico local e pelas precárias condições de trabalho. A indústria têxtil na referida cidade é constituída por milhares de pequenos empreendimentos, muitos de base familiar, isto é, produtores individuais e/ ou pequenas empresas que quase sempre funcionam em espaços domiciliares destinados à produção, ocorrendo majoritariamente sob as formas de subcontratação, terceirização e informalidade, convergindo para a maximização dos lucros dos produtores e dos comerciantes locais (Sebrae, 2019).

Os dados primários foram levantados por meio de entrevistas semiestruturadas com o representante da Associação dos Lojistas do Parque das Feiras de Toritama e com o representante do Sindicato das costureiras, que dispõem de conhecimento acerca do tema e que desejaram contribuir com a pesquisa, bem como da observação não participante, complementadas com o auxílio do diário de campo. Os dados secundários foram obtidos por meio de sites governamentais, de organizações que fazem parte do APL e de institutos de pesquisa, bem como de pesquisas de campo realizadas anteriormente no setor estudado.

O instrumento de coleta de dado foi elaborado a partir da classificação de Arranjos Produtivos Locais proposta pelo Sebrae (2014), que divide os APLs em: Incipientes, em Desenvolvimento e Desenvolvidos. Assim, foram consideradas as seis categorias que constituem o modelo: Liderança, Atores e Cooperação, Recursos Financeiros, Gestão do Processo de Desenvolvimento, Inovação e Tecnologia, Mercado e Competitividade.

Para a análise dos dados, utilizou-se da técnica de análise de conteúdo, que tem como objeto de estudo a fala, busca compreender o conteúdo das mensagens para os emissores por meio de procedimentos sistemáticos indicadores que possibilitem inferir sobre o contexto de produção das informações (Bardin, 2016). Por fim, realizou-se a triangulação entre os instrumentos aplicados para a coleta dos achados Análise documental, entrevistas e observação.

\section{Resultados e discussão}

\subsection{Estágio de desenvolvimento de arranjo produtivo local no setor de confecções}

\subsubsection{Liderança}

As atividades desse APL são desenvolvidas de forma isolada e desarticulada. Grande parte dos empresários não estão conectados a nenhum tipo de associação ou entidade de classe que possam lhes representar e, consequentemente, buscar por melhorias para o desenvolvimento do setor confeccionista (Sebrae, 2019). A tímida interação entre os atores locais pode interferir em diferentes eixos do progresso setorial, especialmente, no que se refere ao compartilhamento de recursos e à disseminação de informações que possibilitam a troca de experiências e a aquisição de conhecimento: 
Toritama hoje é o segundo maior polo de confecção do País, só perde para São Paulo, para o Brás. Então é o seguinte, era pra Toritama, ela ter uma melhor infraestrutura, pra mão de obra mesmo, capacitação dos funcionários, tanto de costureiras, de lavanderias, de atendimento que precisamos também, que o Sebrae poderia fazer uma parceria para curso de atendimento. Então tudo, a maioria 99,99\%, se você conseguir pra fazer uma palestra de atendimento, fazer um curso, é tudo custeado pela associação, que é a associação que administra né (Representante do Parque das Feiras de Toritama).

Outro item mencionado como entrave pelos empresários, são os preços praticados pelos fornecedores de insumos, visto que comprando individualmente, não têm poder de barganha. Isto poderia ser minimizado com a criação de uma central de compras, uma vez que, aumentando o volume de compra junto aos fornecedores, permitiria um maior poder de negociação (Sebrae, 2019).

No município estão presentes agentes que podem contribuir com a difusão de informações tecnológicas e mercadológicas, a promoção de cursos e de eventos técnicos e comerciais, bem como na articulação política e no planejamento estratégico, a exemplo do Sindicato das Indústrias de Vestuário do Estado de Pernambuco, da Câmara dos Dirigentes Lojistas e da Associação Comercial e Industrial de Toritama (Lacerda, 2014). Entretanto, percebe-se que uma das limitações é a ausência de reciprocidade entre as lideranças locais. O representante do Parque das Feiras de Toritama afirmou "A gente recebe hoje clientes de todos os estados do país, mas... a gente deixa a desejar nessa parte da infraestrutura por conta dessas parcerias que não tem". Relativo a isso, o representante do Sindicato das costureiras destacou que "Existe uma competição, quem quer ser o melhor, essa questão do setor, eles não combinam, não conversam".

Deste modo, no que se refere à liderança, observa-se que o APL está no estágio incipiente pois, o setor é relevante em termos locais pelo impacto positivo na arrecadação do município. Mas, os resultados estão aquém da sua potencialidade, pois carece de lideranças legitimadas e de integração entre os atores sociais, especialmente, entre as empresas que atuam com foco individual.

\section{$\underline{4.1 .2}$ Atores e cooperação}

Além das associações de classe apresentadas anteriormente, o setor pode contar com o apoio de órgãos públicos, atores políticos, agente financeiros, centros tecnológicos e acadêmicos. Entre esses atores, destacam-se o Serviço Brasileiro de Apoio às Micro e Pequenas Empresas (Sebrae), o Serviço Nacional de Aprendizagem Industrial (Senai), os Governos estadual e municipal e grupos políticos, a Faculdade de

Moda, entre outros. No entanto, cabe salientar que muitas vezes os empresários desconhecem a disponibilidade dessas instituições (Lacerda, 2014).

Devido à ausência de uma efetiva interação entre esses atores e as empresas, bem como pela falta de cooperação entre o empresariado, o setor utiliza como mecanismo para disseminar informações "uma rádio comunitária ligada o tempo todo, fazendo a propaganda de lojas e serviços em geral" (Representante do Parque das Feiras de Toritama). Para comercializar no condomínio, os empresários precisam cumprir 
alguns requisitos básicos que englobam a formalização e a cooperação financeira necessária para a manutenção do estabelecimento comercial:

Sim, hoje nós estamos já exigindo alguns critérios, pra que você antes que chegue pra estabelecer seu comércio aqui dentro, umas das primeiras coisas é tirar seu CNPJ, então você tem que ir à prefeitura, tem que liberar seu alvará de funcionamento, se cadastrarem aqui pra gente saber quem é a pessoa que está se estabelecendo aqui dentro no centro de compras, porque hoje a gente precisa saber quem é quem, então hoje aqui a gente já tem essas exigências também, a gente já comunica quem tem uma taxa de condomínio que é pra manutenção, o horário que abre o parque, o horário que você pode fazer a manutenção da sua loja. Então existe algumas regras pra gente se estabelecer (Representante do Parque das Feiras de Toritama).

A respeito da exigência de critérios para participar do Sindicato das costureiras, o representante afirmou:

Essa parte aí das empresas, cabe mais ao sindicato patronal. A nossa parte é a do trabalhador, nós corremos atrás, fazemos questão de buscar conhecimento e informar a eles, entendeu?! Mas Toritama e Santa Cruz é o maior índice de informalidade é ai. Você chega numa empresa daquela vê 40 funcionários, ali tem 15 registrados, o resto são informais.

Os relacionamentos entre diferentes atores sociais envolvem incertezas e possibilidades de comportamentos oportunistas, dado que existe assimetria de interesses e de informação entre eles. Assim, além de elos fundamentados na confiança, o setor estabelece regras como medida complementar,

Às vezes o lojista que quer fazer uma propaganda aqui dentro, distribuindo panfletos, então a gente tem um certo limite. Às vezes dia de feira cada um quer colocar um som, a gente também vai lá e bota um som interno (Representante do Parque das Feiras de Toritama).

Assim sendo, verifica-se que na categoria atores e cooperação, o estágio de desenvolvimento do APL é incipiente, dado que não há consenso entre as lideranças locais. A integração entre o poder público e a iniciativa privada é mínima, bem como o relacionamento entre os empresários e as entidades de classe é pouco desenvolvido.

\subsubsection{Recursos financeiros}

O Banco do Brasil e a Caixa Econômica Federal destacam-se entre os agentes financeiros que podem atuar no financiamento do capital de giro, de empréstimos para investimento em capital físico, bem como no fornecimento de microcrédito (Lacerda, 2014). No entanto, o relacionamento com essas instituições financeiras ainda é pouco expressivo, não há ferramentas de apoio suficientes para a eficácia da produção e da venda de mercadorias. Os empresários apontam que o setor de confecções carece de linhas de financiamento a juros diferenciados, bem como de prazos de pagamento mais elástico para aquisição dos insumos (Sebrae, 2019). 
Desta maneira, quanto aos recursos financeiros, o estágio de desenvolvimento do APL é incipiente, uma vez que os agentes financeiros estão presentes, mas não se envolvem de forma proativa no progresso das empresas, e os investimentos para expansão não são executados adequadamente por falta de financiadores de médio e/ou longo prazos e de juros mais adequados.

\subsubsection{Gestão do processo de desenvolvimento}

A articulação com o Governo (Estadual, Municipal e Federal) ainda está em uma fase embrionária:

O Parque das Feiras como é uma instituição privada, nós aqui foi quem construímos, é um condomínio privado. As parcerias que nós temos aqui são mínimas possíveis, com a prefeitura, mas com o governo do Estado não temos parcerias, com o governo federal, e ai o que nós temos é parcerias de incentivo, de um melhoria na parte da infraestrutura, na parte pública que favorece o parque das feiras, como por exemplo, as estradas, segurança para o cliente que vem comprar, trata-se sinalização, a arborização, se tivesse mais arborização... iluminação, nós temos essa dificuldade hoje (Representante do Parque das Feiras de Toritama).

O setor carece da elaboração e da implementação de programas e de políticas públicas que possibilitem a articulação entre esferas de poder e a mobilização de recursos orientados ao desenvolvimento. No entanto, segundo Lacerda (2014), foram elaborados projetos, leis e ações para minorar os impactos ambientais resultantes dos processos, a seguir:

a) Plano Diretor de Toritama, que trata sobre gestão urbana e ambiental, organização social e cidadania, desenvolvimento econômico e distribuição social, infraestrutura e serviços urbanos, recuperação e proteção do patrimônio ambiental e estruturação territorial;

b) ação institucional do Centro Tecnológico da Moda denominada "Desenvolvimento e ajuste tecnológico no processo industrial das lavandeiras do APL da confecção do Agreste de Pernambuco" voltada para a conscientização ambiental;

c) projeto consciência limpa, que busca elevar as lavanderias de beneficiamento à condição de empresas ambientalmente responsáveis, por meio do tratamento e do reaproveitamento dos efluentes oriundos das lavagens do jeans;

d) Lei de resíduos sólidos (14.973/2009) direcionada para que grandes geradores (Acima de 200 litros de resíduos por dia) estabeleçam uma coleta própria;

e) Termo de ajuste de conduta, onde cada lavanderia tem de tratar os seus efluentes em um período de oito a doze meses.

Desta forma, em relação à gestão do processo de desenvolvimento, o APL está no estágio incipiente, dado que a interação entre o meio empresarial e o poder público ainda ocorre de forma tímida, para atender a questões pontuais, não existindo um plano para o desenvolvimento e ações integradas. No 
entanto, cabe realçar que existe uma sensibilização no que corresponde à dimensão ambiental, o que se configura como um aspecto positivo para o Arranjo, dado que as iniciativas sustentáveis são imprescindíveis para a segmento da moda, que é reconhecida pelo uso intensivo de recursos naturais e pelos impactos resultantes da disposição inadequada de resíduos.

\section{$\underline{4.1 .5 \text { Inovação e tecnologia }}$}

Existem eventos e ações de melhorias orientadas ao APL, a exemplo do Festival do Jeans, do Desfile das coleções e do Festival de Cultura e Moda Pernambucana. Além de atores como o Instituto Tecnológico de Pernambuco (ITEP), a Faculdade da Moda e o Centro Tecnológico da Moda, que podem interagir com o empresariado por meio da realização de pesquisas e aspectos ligados a design, a modelagem, a produção e qualidade, concentrando-se em produtos do jeans. Mas, muitas vezes, essas ações são desconhecidas pelos empresários (Lacerda, 2014).

Ademais, tendo em vista ser a demanda sempre em alta, não existe muito interesse na criação de novas linhas de produção. O estágio tecnológico das máquinas e dos equipamentos é parcialmente automatizado, dado que há algumas limitações com a baixa escolaridade dos seus funcionários, além da falta de cursos técnicos e gerenciais (Sebrae, 2019).

À vista disso, constata-se que em inovação e tecnologia o estágio de desenvolvimento do APL é incipiente, uma vez que os centros de pesquisa ou de profissionalização estão presentes para contribuir na elaboração e na implementação de novos processos produtivos, bem como os empresários podem participar eventualmente como visitantes em feiras do setor. No entanto, a ausência de integração entre os atores sociais impede a difusão da inovação e, muitas vezes, a disponibilidade dessas estratégias não são reconhecidas pelos empresários, ademais, há indisposição de investir na atualização de tecnologias e das operações.

\section{$\underline{4.1 .6 \text { Mercado e competitividade }}$}

Existe no município uma forte concorrência, dado que um grande número de empreendimentos desenvolve a mesma atividade, sendo este fator considerado como o principal obstáculo para a ampliação do negócio. Como forma de buscar a melhoria contínua e um diferencial competitivo, as empresas precisam investir em inovações quanto ao "design", à tecnologia, à capacitação, às máquinas e equipamentos, entre outros (Sebrae, 2019).

Relativo às contribuições geradas pelas parcerias entre as empresas para o setor e para o desenvolvimento local, o representante do Sindicato das costureiras destacou "cada uma tem seu plano de trabalho, entendeu?! A partir do momento que eu começo as parcerias, se você melhorar no seu setor, tem um conhecimento do setor, a tendência é melhorar pra todos, não só pra gente, pra todos". 
O produto apresenta forte identidade local, o mercado regional é conhecido e atua em escala nacional. O significado da calça jeans produzida por Toritama é fruto de iniciativas conjuntas de uma cadeia de atores, os quais empreendem culturalmente ao articularem significados a esse artefato. Essas roupas produzidas na referida cidade são escoadas pelo Brasil através dos milhares de comerciantes, atacadistas e lojistas de diferentes estados do País, que vêm semanalmente à Feira do Jeans realizarem suas compras e abastecerem suas lojas (Sebrae, 2019).

Com base nas informações, quanto ao mercado e competitividade, o APL está no estágio de desenvolvimento, dado que os produtos são identificados com alguma característica sociocultural local, as empresas apresentam-se mais competitivas e atuam no nível de mercado (nacional). Entretanto, ainda que exista um cenário propício ao progresso do APL nesta categoria, o setor necessita da realização efetiva de pesquisas relativas a inovações técnicas e a questões mercadológicas, bem como carece de melhorias na articulação entre as empresas, para que seja possível alcançar resultados de forma conjunta, por meio de uma relação equilibrada entre a cooperação e a competição.

\subsection{Discussão dos resultados}

O Quadro 2 apresenta um resumo sobre a identificação do estágio de desenvolvimento do Arranjo Produtivo Local de confecções fixado no município Toritama (PE), possibilitada por meio dos critérios estabelecidos pelo Serviço Brasileiro de Apoio às Micro e Pequenas Empresas - Sebrae (2014). O quadro é composto pelas categorias do modelo e pelos resultados obtidos no APL. Para cada categoria foi atribuído os conceitos de incipiente, em desenvolvimento e desenvolvido conforme a intensidade e a presença dos critérios utilizados para classificação do APL. Vale ressaltar que mesmo que em uma categoria o setor tenha o resultado desfavorável, não significa necessariamente que essa não tenha sido contemplada e sim que possui um desempenho inferior ao caracterizado no modelo aplicado.

Quadro 2 - Estágio de desenvolvimento do APL confeccionista de Toritama (PE)

\begin{tabular}{|l|l|}
\hline \multicolumn{1}{|c|}{ Categorias } & Estágio de desenvolvimento \\
\hline 1. Liderança & Incipiente \\
\hline 2.Atores e cooperação & Incipiente \\
\hline 3.Recursos financeiros & Incipiente \\
\hline 4.Gestão do processo de desenvolvimento & Incipiente \\
\hline 5.Inovação e tecnologia & Incipiente \\
\hline 6.Mercado e competitividade & Em desenvolvimento \\
\hline
\end{tabular}

Fonte: Dados da pesquisa (2018).

A análise do quadro 2 permite entender, segundo o proposto pelo modelo do Sebrae (2014) que, em relação ao estágio de desenvolvimento, o APL estudado está na fase incipiente. Conforme exposto na seção anterior, o município concentra órgãos públicos, associações de classe, atores políticos, agente financeiros, centros tecnológicos e acadêmicos que podem contribuir com a difusão de informações tecnológicas e mercadológicas, a promoção de cursos e de eventos técnicos e comerciais, a realização de 
pesquisas, o fornecimento do capital de giro e de microcrédito, etc. Entre esses atores, destacam-se o Sindicato das Indústrias de Vestuário do Estado de Pernambuco, a Câmara dos Dirigentes Lojistas, a Associação Comercial e Industrial de Toritama, o Serviço Brasileiro de Apoio às Micro e Pequenas Empresas, o Serviço Nacional de Aprendizagem Industrial, o Banco do Brasil, a Caixa Econômica Federal, o Instituto Tecnológico de Pernambuco, entre outros.

A coesão das estratégias dessas instituições é indispensável para o desenvolvimento do APL, mas a atuação dessas instituições e do empresariado é desarticulada. A falta de convergência entre as lideranças locais (poder público, empresas e outras instituições) é uma das principais limitações do setor. Assim, as empresas focam em resultados individuais, o poder público e o empresariado não articulam estratégias conjuntas visando o progresso do APL, bem como não existe interação entre os demais agentes que buscam melhorias para o setor. Desse modo, esse aspecto contribui, principalmente, para o não reconhecimento de ações disponíveis para as empresas, como oportunidades de capacitações, de inovações, de aquisição de recursos, etc.

Todas as dimensões analisadas apresentaram resultados desfavoráveis. Esse aspecto reforça a necessidade de estratégias, de políticas e de programas que visam o incremento da competitividade e o desenvolvimento do APL equilibrando os objetivos econômicos, sociais e também ambientais, visto que no município existem estratégias que visam a redução de impactos ambientais provocados pelo setor. Os limites impostos pelos modelos de crescimento que desconsideraram a escassez dos recursos naturais e os aspectos sociais em sua dinâmica podem interferir na busca pelo aumento das vantagens competitivas dado que, sob uma lógica sistêmica, há uma interdependência, ou seja, a capacidade dos agentes de um APL conseguirem vantagens competitivas vai depender das possibilidades de desenvolvimento local (Souza, 2010). Nesse sentido, quanto aos aspectos passíveis de melhorias é possível destacar:

a) APL necessita de um plano de ações integradas para o desenvolvimento setorial, defendendo interesses coletivos, bem como incluindo estratégias que possibilitem o uso otimizado de recursos naturais e a redução de impasses ambientais.

b) É preciso monitorar e acompanhar o desempenho das ações estabelecidas a partir de um planejamento estratégico voltado para o setor, bem como avaliar a contribuição do APL para o desenvolvimento local por meio de metodologias fornecidas na literatura, a exemplo do modelo proposto por Olivares e Dalcol (2010).

c) As empresas precisam de maior cooperação da produção à distribuição de bens e serviços, a exemplo de ações coletivas de investimento em novas tecnologias, em inovação e em novos produtos, da disseminação e da utilização de conhecimento, etc.

d) Além de maior integração entre os atores locais, é necessário o uso de meios mais eficazes para disseminar oportunidades e ações (inovações, financiamento, qualificação, palestras, etc) oferecidas pelas instituições locais. 
Com base em Lübeck et al. (2019), é possível apontar que essas adequações são essenciais para alcançar o progresso do APL e o desenvolvimento local, pois visam a coordenação dos múltiplos relacionamentos constituídos entre os atores locais, especialmente, apoiado em mecanismos de cooperação e de confiança.

Esta estrutura organizacional tem potencial para beneficiar todos os membros que o compõe, desde que exista maior articulação entre as lideranças locais; mas, conforme salientado por Oprime et al. (2011), para que essa integração seja promovida, é necessário que a administração possua uma visão sistêmica. Assim, ao considerar a realidade deste APL, essa atuação estratégica e integrada requer dos atores locais mudança de valores e a construção de uma identidade coletiva.

Além do estímulo às parcerias e ao cooperativismo, outro desafio identificado para o APL diz respeito à coordenação das práticas de investimento em inovação e em tecnologias, a oferta de recursos e de serviços financeiros, aos programas de capacitação, etc. Esse resultado converge com o apontado por Trippl et al., (2015) quando argumentaram a respeito da existência e da possibilidade de influência de múltiplos fatores no desenvolvimento de APLs, tais como: tecnologias, potencialidades das empresas, processos de aprendizagem, etc. Relativo a isso, Brenner e Schlump (2011) salientam que a educação desempenha um papel relevante de apoio ao desenvolvimento de APLs em todas as etapas do ciclo de vida. Nesse contexto, pesquisas específicas, palestras ou programas de educação são medidas de curto prazo que atendem às demandas locais.

Esses resultados sugerem uma diversidade de caminhos que podem ser trilhados pelo APL durante diferentes fases seu ciclo de vida, conforme salientado por Trippl et al., (2015). Permitem considerar as especificidades do setor confeccionista de Toritama (PE), o que é essencial para aplicação de ações adequadas à realidade da região, como argumentado por Tizziotti et al., (2019). Assim, foram apontadas limitações e possibilidades que podem proporcionar uma orientação geral à sociedade, em especial, às empresas e ao poder público na tomada de decisão e na formulação de estratégias e de políticas.

\section{Considerações finais}

O estudo objetivou classificar o estágio de desenvolvimento do Arranjo Produtivo Local de confecções do município de Toritama (PE) a partir do modelo proposto pelo Serviço Brasileiro de Apoio às Micro e Pequenas Empresas - Sebrae (2014), que divide os Arranjos em: Incipientes, em Desenvolvimento e Desenvolvidos. Esse modelo foi selecionado pelo fato de ser direcionado à realidade brasileira e em razão da abrangência e relevância dos critérios que permitem um enfoque analítico e sistêmico das dinâmicas de APLs em seis categorias: liderança, atores e cooperação, recursos financeiros, gestão do processo de desenvolvimento, inovação e tecnologia, mercado e competitividade.

Os resultados apontam que nas categorias liderança, atores e cooperação, inovação e tecnologia, recursos financeiros e gestão do processo de desenvolvimento, o APL encontra-se no estágio incipiente. Observou-se que as empresas atuam com foco individual, as lideranças não são legitimadas e não se 
envolvem de forma proativa no progresso das organizações, especialmente quanto à oferta de recursos e à coordenação das práticas de investimento em inovações, tecnologias, programas de capacitação, etc. Quanto à categoria mercado e competitividade, o setor está no estágio de desenvolvimento, os produtos apresentam identidade local e o APL é destaque em território nacional. Entretanto, vale realçar que esse resultado não expressa que os critérios analisados não necessitam de melhorias.

Deste modo, quanto ao estágio de desenvolvimento, conclui-se que o Arranjo Produtivo Local de confecções do município de Toritama (PE) está na fase incipiente. Verificou-se que há um ambiente propício às relações de cooperação. Entretanto, a falta de consenso entre as lideranças locais pode se configurar como um empecilho para o progresso do setor. Assim, é necessário que exista mudança no que diz respeito à integração entre esses atores sociais, para que seja possível alcançar a eficiência coletiva e as vantagens proporcionadas por essas estruturas organizacionais. Baseado em Lübeck et al. (2019) e Oprime et al. (2011) observou-se que esses ajustes são fundamentais para este setor, pois o desenvolvimento de APLs leva em conta as relações sociais constituídas entre seus membros, apoiadas em mecanismos como confiança e cooperação.

Este trabalho contribuiu com a ampliação dos debates sobre o ciclo de vida de APLs, que segundo Trippl et al. (2015) possibilita compreender os fatores que podem desencadear o desenvolvimento dessas estruturas organizacionais. Ademais, consolidou informações sobre um dos APLs de confecções mais relevantes para a economia do Estado de Pernambuco, o que possibilita a identificação dos aspectos passíveis de melhorias e a redefinição de políticas de apoio ao desenvolvimento do setor. Essas contribuições se refletem não apenas no campo empresarial, mas também na área governamental, pois para serem objeto de políticas públicas, os APLs devem ser antes estudados no sentido de identificar suas estruturas produtivas e de governança, bem como suas formas de atuação no cenário de negócios. Portanto, é preciso conhecer as especificidades de cada APL, como apontado por Tizziotti et al., (2019).

Este trabalho possui limitações de ordem teórico-metodológica: teórica, APL é um construto complexo, devido à quantidade de elementos que precisam ser considerados, podendo assumir diferentes significados a partir do contexto estudado; metodológica, o trabalho não teve como objetivo ser um estudo específico sobre as empresas, assim, foi realizado no setor de modo geral tomando como referência alguns atores sociais. Entretanto, salienta-se também a pertinência do conteúdo coletado e a qualidade das entrevistas, que mitigaram essa limitação.

Para trabalhos futuros sugere-se que seja investigado o estágio de desenvolvimento de outros APLs, inclusive de outros setores, bem como seja efetuado a comparação destes resultados com outros estudos, permitindo a possibilidade de em um futuro serem feitas generalizações sobre APLs.

\section{Referências}

Alderete, M. V., \& Bacic, M. J. (2018). Local Productive Arrangements and local development in nonmetropolitan municipalities of Sao Paulo, Brazil. Cuadernos de Gestion, 18(1), 103-124.

https://doi.org/10.5295/cdg.150561ma. 
Araújo, A. C. da M., Silva, A. L. L. da, Souza, S. M. A. De, Lacerda, C. C. de O., \& Gonçalves, G. A. da C. (2016). Análise da competitividade do cluster de confecções no município de Campina Grande $P B$. Artigo apresentado no XXXVI Encontro Nacional de Engenharia de produção 2016, João Pessoa, Brasil.

Bardin, L. (2016). Análise de conteúdo. São Paulo: Edições 70.

Brasil. Ministério da Indústria, Comércio Exterior e Serviços (2018). APL. Recuperado de http://www.mdic.gov.br/index.php/competitividade-industrial/arranjos-produtivos-locais.

Brenner, T., \& Schlump, C. (2011). Policy Measures and their Effects in the Different Phases of the Cluster Life Cycle. Regional Studies, 45(10), 1363-1386. https://doi.org/10.1080/00343404.2010.529116.

Dyba, W., Stryjakiewicz, T., \& De Marchi, V. (2019). Knowledge sourcing and cluster life cycle-a comparative study of furniture clusters in Italy and Poland. European Planning Studies, 10(3), 1-20. https://doi.org/10.1080/09654313.2019.1701996.

Elola, A., Valdaliso, J. M., Franco, S., \& López, S. M. (2017). Public policies and cluster life cycles: insights from the Basque Country experience. European Planning Studies, 25(3), 539-556. https://doi.org/10.1080/09654313.2016.1248375.

Gancarczyk, M., \& Bohatkiewicz, J. (2018). Research Streams in Cluster Upgrading. A Literature Review. Journal of Entrepreneurship, Management and Innovation, 14(4), 17-42. https://doi.org/10.7341/20181441.

Iacono, A., \& Nagano, M. S. (2009). Interação e cooperação em arranjos produtivos locais: identificação e análise dos fatores inibidores. Artigo apresentado no XII Simpósio de Administração da Produção, Logística e Operações Internacionais 2009, São Paulo, Brasil.

Instituto Brasileiro de Geografia e Estatística, IBGE (2018a). Banco de Dados/Cidades:Santa Cruz. Recuperado em 7 junho, 2018, de https://cidades.ibge.gov.br/brasil/pe/santa-cruz/panorama.

Instituto Brasileiro de Geografia e Estatística, IBGE (2018b). Banco de Dados/Cidades: Toritama. Recuperado em 7 junho, 2018, de https://cidades.ibge.gov.br/v4/brasil/pe/toritama/panorama.

Instituto Brasileiro de Geografia e Estatística, IBGE (2018c). Banco de Dados/Cidades: Caruaru. Recuperado em 7 junho, 2018, de https://cidades.ibge.gov.br/brasil/pe/caruaru/panorama.

Lacerda, C. C. de O. (2014). Efeitos da competitividade no cluster de confecções do agreste pernambucano : um estudo focalizado no município de Toritama - PE. Trabalho de conclusão de curso, Universidade Estadual da Paraíba, Campina Grande, PB, Brasil.

Lübeck, R. M., Wittmann, M. L., \& Silva, M. S. da. (2019). Afinal, Quais variáveis caracterizam a existência de Cluster Arranjos Produtivos Locais (APLs) e dos Sistemas Locais de Produção e Inovação (Slpis)? Journal of Chemical Information and Modeling, 53(9), 1689-1699. https://doi.org/10.1017/CBO9781107415324.004.

Malhotra, N. K. (2012). Pesquisa de Marketing. Porto Alegre: Bookman.

Martin, R., \& Sunley, P. (2011). Conceptualizing Cluster Evolution: Beyond the Life Cycle Model? Regional Studies, 45(10), 1299-1318. https://doi.org/10.1080/00343404.2011.622263.

Menzel, M. P., \& Fornahl, D. (2011). Cluster Life Cycles - Dimensions and Rationales of Cluster 
Development. Jena Economic Research Papers. 76. https://doi.org/10.2139/ssrn.1025970.

Olivares, G. L., \& Dalcol, P. R. T. (2010). Proposta de um sistema de indicadores para medir o grau de contribuição dos aglomerados produtivos para o desenvolvimento local e regional. Revista Brasileira de Gestao e Desenvolvimento Regional, 6(2), 188-218.

Oprime, P. C., Tristão, H. M., \& Pimenta, M. L. (2011). Relationships, cooperation and development in a Brazilian industrial cluster. International Journal of Productivity and Performance Management, 60(2), 115-131. https://doi.org/10.1108/17410401111101467.

Ostergaard, C. R., \& Park, E. (2015). What Makes Clusters Decline? A Study on Disruption and Evolution of a High-Tech Cluster in Denmark. Regional Studies, 49(5), 834-849. https://doi.org/10.1080/00343404.2015.1015975.

Prado, A. A. de A., Moreno Ferragi, E., Gama Boaventura, J. M., \& Telles, R. (2013). Contribuição da Abordagem System Dynamics na Compreensão da Competitividade de Clusters de Negócios. Revista Ibero-Americana de Estratégia - RIAE, 12(4), 40-66. https://doi.org/10.5585/riae.v12i4.2011.

Serviço Brasileiro de Apoio às Micro e Pequenas Empresas, Sebrae (2019). Estudo Econômico das Indústrias de Confecções de Toritama/PE. Recife: Sebrae.

Serviço Brasileiro de Apoio às Micro e Pequenas Empresas, Sebrae (2014). Estudo econômico do Arranjo Produtivo Local de confecções do Agreste Pernambucano. Brasília: Sebrae.

Serviço Brasileiro de Apoio às Micro e Pequenas Empresas, Sebrae (2012). Estudo econômico do arranjo produtivo local de confecções do agreste pernambucano. Recife: Sebrae.

Silva, A. L. L. da, Araújo, A. C. da M., Souza, S. M. A. De, \& Gonçalves, G. A. da C. (2015). Análise da competitividade do cluster de confecções de Santa Cruz do Capibaribe-PE. Artigo apresentado no IV Simpósio Internacional de Gestão de Projetos, Inovação e Sustentabilidade 2015, São Paulo, Brasil.

Souza, S. M. A., Bezerra, P. R. S., Rocha, S. F., \& Gonçalves, G. A. C. (2020). Classificação de Arranjos Produtivos Locais a Partir do modelo teórico proposto pelo Sebrae (2014): Um Estudo No Setor De Confecções Do Município De Caruaru - Pe. Qualitas Revista Eletrônica, 21(1), 188-208. https://doi.org/10.18391/req.v21i1.5176.

Souza, S. M. A. Relações entre as formas de Governança de Arranjos produtivos locais com a Competitividade e o Desenvolvimento local sustentável: um estudo exploratório no setor de confecções em Campina Grande - PB. Tese de Doutorado. Universidade Federal de Campina Grande, Campina Grande, PB, Brasil

Tizziotti, C. P. P., Truzzi, O. M. S., \& Barbosa, A. de S. (2019). Arranjos Produtivos Locais: uma análise baseada na participação das organizações locais para o desenvolvimento. Gestão \& Produção, 26(2), 01-14. https://doi.org/10.1590/0104-530x-2579-19.

Trippl, M., Grillitsch, M., Isaksen, A., \& Sinozic, T. (2015). Perspectives on Cluster Evolution: Critical Review and Future Research Issues. European Planning Studies, 23(10), 2028-2044. https://doi.org/10.1080/09654313.2014.999450.

Yin, R. K. (2015). Estudo de caso. Porto Alegre: Bookman. 